\title{
Surface topography of the female bladder trigone
}

\author{
R DAVIES AND AC HUNT
}

From the Department of Histopathology, Plymouth General Hospital, Plymouth, Devon, UK

SUMMARY Cystoscopic biopsy specimens of the bladder trigone of young women with recurrent urinary infections were examined by scanning electron microscopy. The superficial cells of the thickened squamous epithelium of the trigone have either a microridged, microvillous, or mixed pattern. In one case, bacteria were found adherent to all these types of surface. Some cells have a microvillous surface and a cobblestone pattern with long, clubbed microvilli and resemble the cells found in malignant and premalignant states.

Humphrey Kay, in his oncological researches, has studied bladder cancer, ${ }^{12}$ and in an issue of the Journal of Clinical Pathology published in his honour it is appropriate to describe an investigation of the bladder which has some relevance to the subject of neoplasia.

The ultrastructural surface topography of the normal human bladder has been well described, ${ }^{3}$ but little information is available on the appearances of the human female trigone mucosa. The practical difficulties in obtaining fresh material for examination are obvious, and series large enough for normal variations to be observed, for example, during the menstrual cycle, have not been described. Most published work on scanning electron microscopy of the normal bladder is related to the changes found in malignant and premalignant epithelium. ${ }^{3} 4$

\section{Material and methods}

In the present study cytoscopic biopsy specimens of the trigones of 18 women with mild recurrent attacks of urinary infection were examined by light microscopy and by transmission and scanning electron microscopy. Three normal bladders from young women removed during postmortem nephrectomy for transplantation were similarly examined. A number of bladders from routine necropsies have been examined, but the mucosa is rapidly damaged by autolysis and is seldom of value.

The histories of all the patients were similar. They complained of recurrent attacks of frequency, dysuria, and stinging on micturition. Most, but not all, had had a positive urine culture at some stage in their illness, but every one had sterile urine immediately before cystoscopy. The total length of history varied from four months to eight years. The younger patients tended to have a longer history than the older, partly because cystoscopy was performed earlier in the latter.

The cystoscopic appearances were similar in the whole group. The abnormalities were confined to the trigone, which had an abnormal greyish, heapedup mucosa, sometimes with a surrounding hyperaemic cuff. This appearance in women with urinary symptoms is sometimes known as pseudomembranous trigonitis despite the fact that signs of active inflammation are absent.

Biopsy specimens were divided in two before fixation. One-half was fixed in buffered neutral formalin and embedded and sectioned in the normal way. The other half was fixed in $5 \%$ buffered glutaraldehyde, washed, dehydrated, treated with amyl acetate, and critically point-dried, gold-coated, and examined with a Joel JSM 35c scanning electron microscope. Some specimens were also examined by transmission electron microscopy. After scanning electron microscopy had been performed, some of the gold-coated specimens were embedded and sectioned for conventional light microscopy. Although the scanning electron microscopic processing interfered with the histological appearances, the type of mucosa was easily determined histologically.

\section{Results}

LIGHT MICROSCOPY

Our findings were similar to those of Henry and 


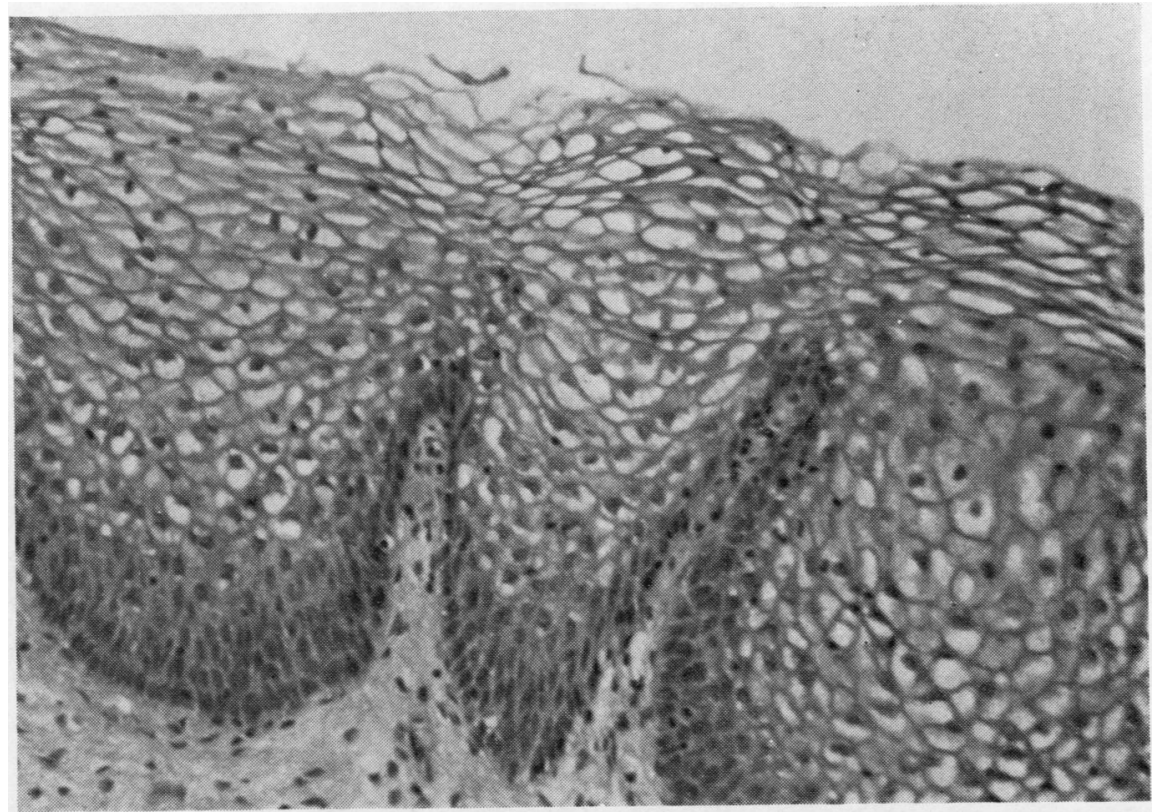

Fig. 1 Trigonal biopsy specimen showing squamous mucosa. Haematoxylin and eosin $\times 500$.

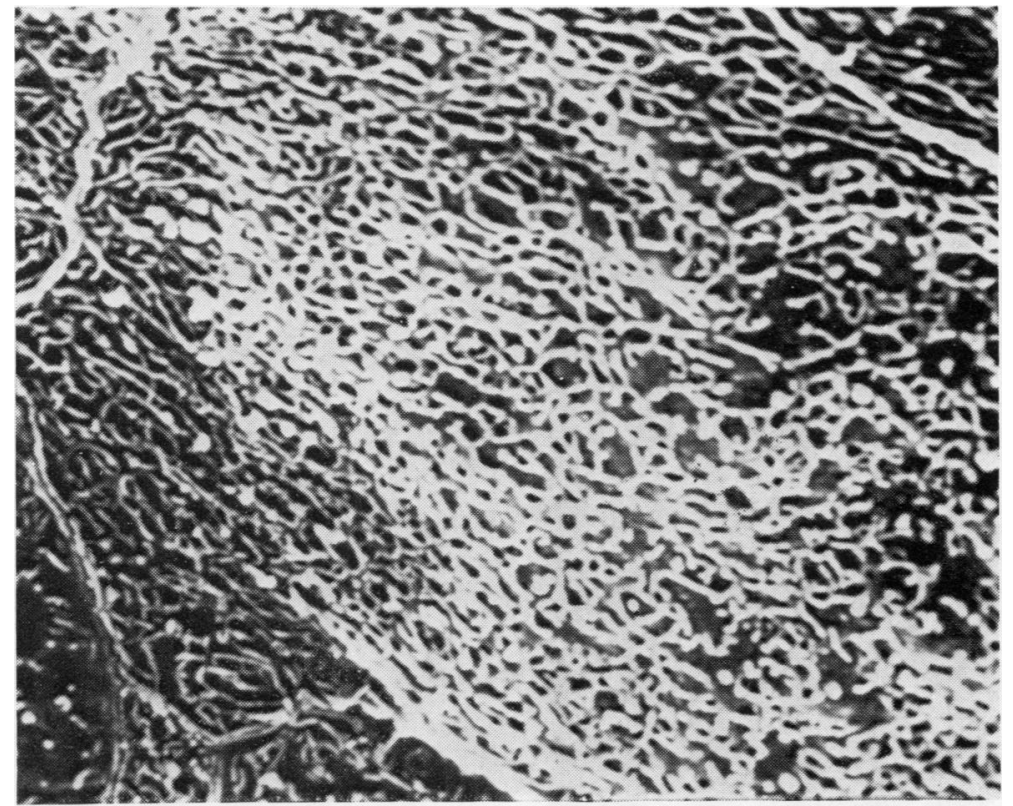

Fig. 2 Surface of trigonal squamous epithelium showing microridges. Scanning $E M \times 2600$. 

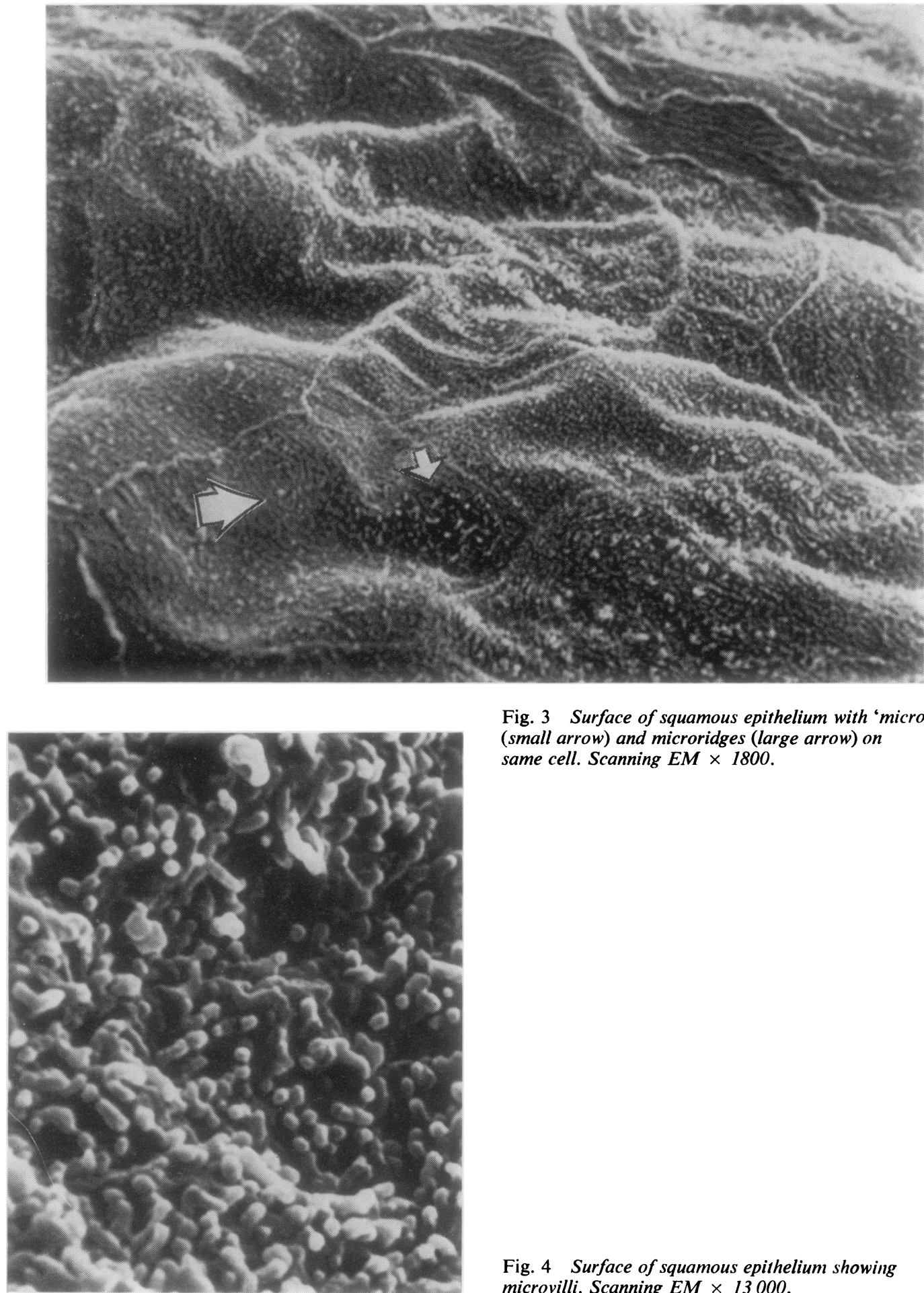

Fig. 3 Surface of squamous epithelium with 'microvilli' (small arrow) and microridges (large arrow) on same cell. Scanning EM $\times 1800$.

Fig. 4 Surface of squamous epithelium showing microvilli. Scanning EM $\times 13000$. 


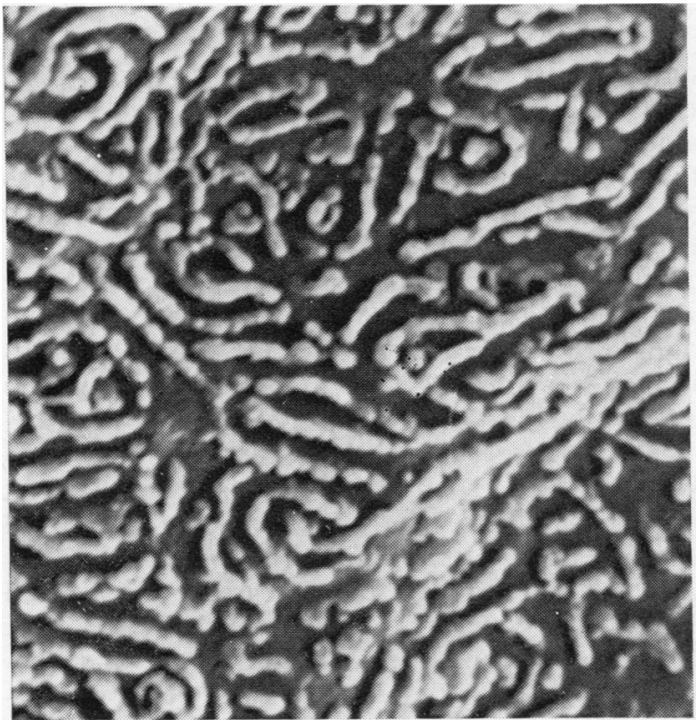

Fig. 5 Surface of squamous epithelium showing microridged pattern. Scanning EM $\times 7800$.

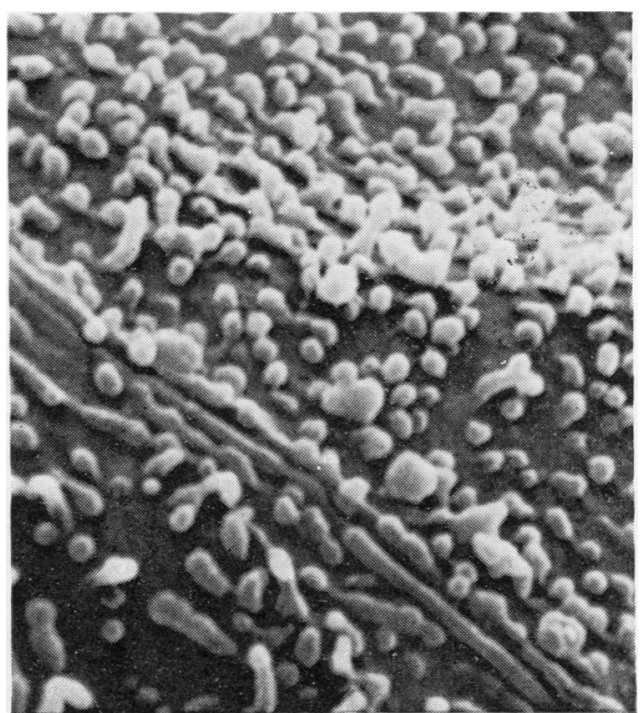

Fig. 7 Surface of squamous cell showing long and clubbed microvilli. Scanning EM $\times 10000$.

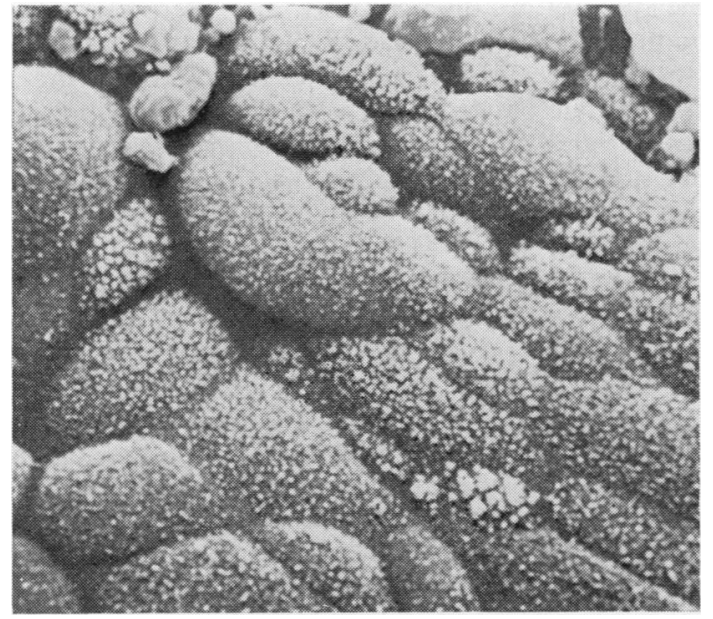

Fig. 6 Surface of transitional epithelium showing 'cobblestone' appearance and microvilli. Scanning EM $\times 1600$.

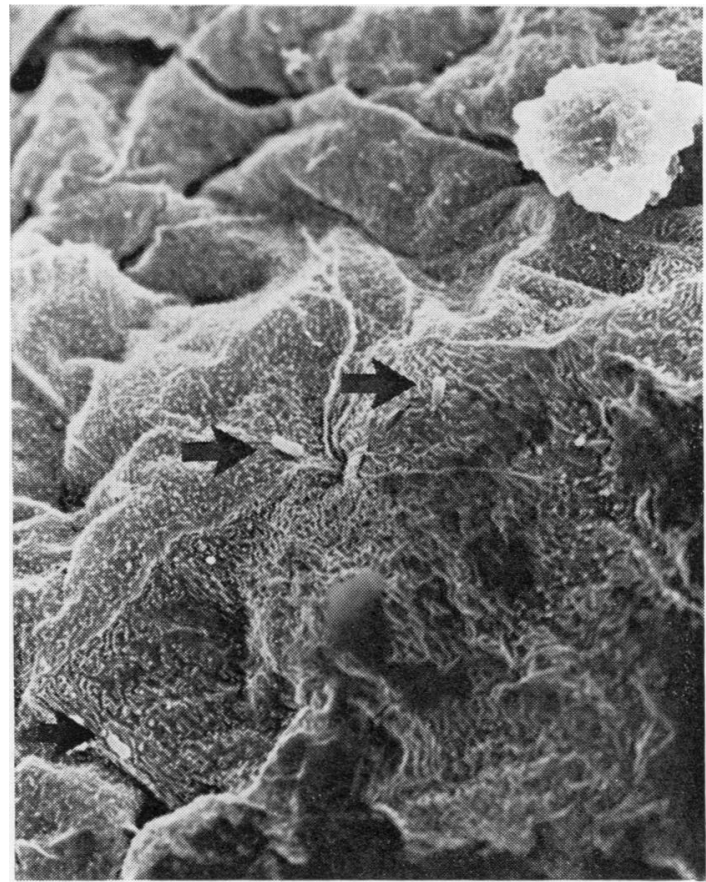

Fig. 8 Bladder trigone. Arrows indicate bacilli on surface of squamous epithelium. Scanning EM $\times 1300$. 
Fox. ${ }^{5}$ The mucosa was squamous (Fig. 1) with occasional transitional cell islands. There were often indications of underlying oedema and vascular dilatation but no significant inflammation. The normal young adult female trigones had a very thin layer of squamous epithelium which did not cover the whole of the trigonal area.

SCANNING ELECTRON MICROSCOPY

Although the light microscopic appearance of the trigonal squamous epithelium in both the normal and abnormal trigones is similar to that of the squamous epithelium of the vagina, the surface topography is more variable. In the vagina, the surfaces of the cells have regular, long microridges and no microvilli. A similar appearance is seen in the majority of the squamous cells of the trigonal

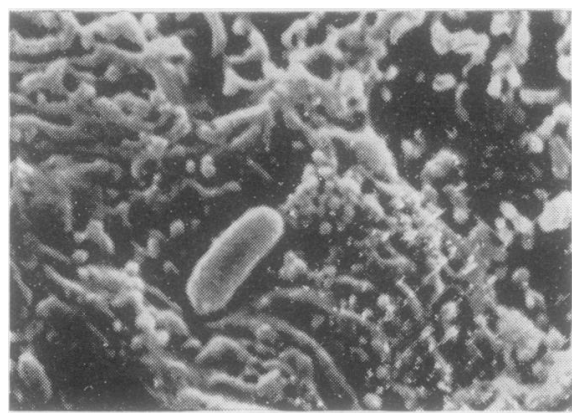

Fig. 9 A bacillus adherent to 'microridged' surface epithelium. Scanning EM $\times 3600$.

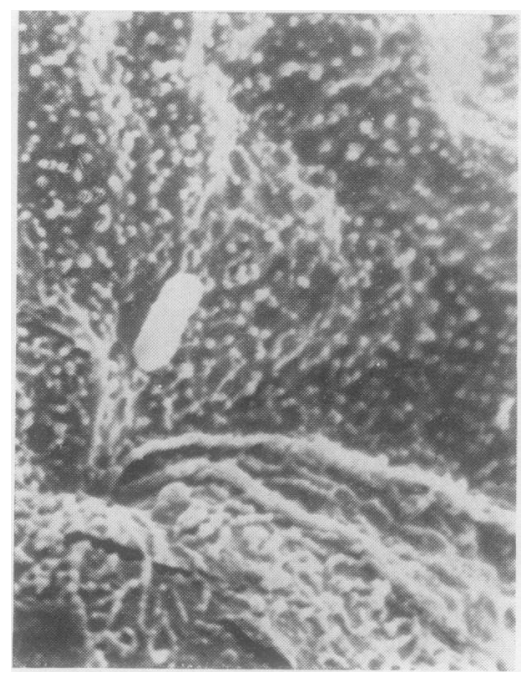

Fig. 10 Bacillus adhering to 'micro-villous' surface epithelium. Scanning $E M \times 4000$. biopsies (Fig. 2) and the normal controls. In the trigonal biopsies and, to a lesser extent, in the normal controls, there are, in addition, many squamous cells with both microridges and microvilli on the same cell (Fig. 3). Some cells show mainly microvilli (Fig. 4) and some microridges (Fig. 5). In the areas that appear transitional by light microscopy, the cells have microvilli only and a domed, raised, 'cobblestone' appearance (Fig. 6). A few similar areas were also observed in the normal controls. Many of the microvilli on both squamous and transitional cells are long and clubbed and vary in size and length (Fig. 7).

A most interesting finding was in a patient 25 ? years old with a three-year history of recurrent $\dot{\omega}$ urinary symptoms. The urine had often contained $\stackrel{+}{\dot{\omega}}$ pus, and Escherichia coli and proteus had repeatedly $\omega$ been cultured from it. Before cystoscopy she had ${ }_{\infty}$ been treated with large doses of septrin, and at the 을 time of cystoscopy the urine was sterile and contained no pus. At biopsy we were able to demonstrate rod-shaped bacteria attached to the epithelium of the bladder trigone (Fig. 8). In some areas they $\stackrel{\Im}{工}$ were lying on microridged epithelium (Fig. 9) and in others they were attached to epithelium with microvilli (Fig. 10). We believe that these findings are genuine and are not due to contamination. The organisms were only on the mucosal surface. Other biopsy specimens were processed at the same time with common reagents, and this specimen had not been stored for any length of time.

\section{Discussion}

The findings in this series are relevant not only to the study of cystitis but also to the interpretation of findings described in bladder neoplasia. The demonstration of cells bearing microvilli and having a cobblestone pattern is surprising in view of the suggested value of scanning electron microscopy in the diagnosis of bladder cancer. An appearance such as this outside the trigone is said to indicate malignancy or premalignancy. ${ }^{4}$ The microvilli in malignant and premalignant bladders are often described as long, clubbed, and pleomorphic, but many of the villi in $N$ our series also show this type of change, especially if the precaution is taken of examining the specimen at different angles of tilt. It seems unlikely that the women in our series could have had premalignant 2 changes in the bladder trigone. Most are below the age of 40 and the youngest was only 14 years old at the time of biopsy. Bladder carcinoma is less common in the female than in the male, ${ }^{6}$ and there is no proven association of bladder carcinoma with recurrent urinary infection of the female. The trigonal epithelium of our patients shows no histological signs 
of premalignancy. The finding of microvilli anywhere in the bladder in the absence of malignancy or premalignancy suggests that the presence of microvilli cannot be a specific neoplastic change. It seems probable that they are only a reflection of the speed at which intermediate cells are reaching the surface of the epithelium. Our findings support those of Koss et al. ${ }^{7}$ who state that $35 \%$ of benign urothelial cells in the urine are characterised by the presence of microvilli, and it is their view that 'the application of SEM to the diagnosis of urothelial carcinoma in urine is of uncertain benefit, pending further studies'. It is also suggested that the presence of microvilli on exfoliated cells, not only from urinary sediment but from the pleura and peritoneal effusions, is an indication of malignancy, 89 and it seems that these claims should be carefully examined.

Our findings shed no light on the pathogenesis of the condition of pseudomembranous trigonitis. The extent of squamous change in the normal trigone is said to be related to oestrogen secretion. In only about half of our patients was the menstrual status recorded at the time of cystoscopy; some were in the first and others in the second half of the cycle. There was no obvious difference histologically or by SEM in the two groups.

It is currently proposed that bacteria are more adherent to the epithelial cells in the periurethral region in women prone to urinary infections. Kallenius and Winberg, ${ }^{10}$ for example, showed that a greater number of a pyelonephritic strain of $E$. coli adhered to washed periurethral cells from infection-prone girls than from normal controls, irrespective of whether or not they had urinary tract infection at the time of investigation, and there is evidence that features of both the organism and the mucosal cells are important. The findings in our patient with organisms on the mucosa suggest that bacteria may adhere to either ridged or microvillous surfaced cells. The question also arises whether the trigone is an area in which organisms can remain adherent between attacks, and further research is indicated.

We are grateful to $\mathbf{M r} \mathbf{J}$ Hammond, urological surgeon, Plymouth General Hospital, for initiating our interest in the trigone and for all his help. Thanks are also due to Plymouth Polytechnic and particularly to Brian Lakey for the use of the scanning electron microscope; to J Siewruk for photography; and to Mrs SJ Davies for typing the manuscript.

\section{References}

${ }^{1}$ Wallace DM, ed. A note on the use of human bladder carcinomas in quantitative oncology. Tumours of the bladder. Livingstone, 1959;194-8.

${ }^{2}$ Kay H, Wallace DM. A and B antigens of tumour arising from urinary epithelium. J Nat Cancer Inst 1961;26: 1349-65.

${ }^{3}$ Newman J, Hicks RM. Detection of neoplastic and preneoplastic urothelıa by combined SEM and TEM of urinary surface of human and rat bladder. Histopathology 1977;1:125-35.

- Tannenbaum M. Ultrastructural pathology of human urinary bladder. In: Trump BF, Jones RT, eds. Diagnostic electron microscopy. Vol 2;221-67

${ }^{5}$ Henry L, Fox M. Histological findings in pseudomembranous trigonitis. J Clin Pathol 1971;24:605-8.

${ }^{6}$ Miller, A Mitchell JP, Brown NJ. The Bristol bladder tumour registry. Br J Urol 1969;Suppl 61.

7 Koss L, Kahan AV, Domagala W. The ultrastructure of surfaces of positively identified cells in the human urinary sediment. Acta Cytol 1979;23:147-55.

${ }^{-}$Domagala W, Woyke S. TEM and SEM studies of cells in effusions. Acta Cytol 1975;19:214-23.

9 Jacobs JM, Cohen SM. SEM on bladder cells. Acta Cytol $1971 ; 21: 3-4$.

${ }^{10}$ Kallenius G, Winberg J. Bacterial adherence to epithelial cells in girls prone to urinary tract infection. Lancet 1978 ;ix :540-3.

Requests for reprints to: Dr AC Hunt, Department of Histopathology, Plymouth General Hospital, Plymouth PL4 8NN. 